\title{
Violence in Secondary Schools of the North West Region of Cameroon
}

\author{
Gladys Ngoran \\ Department of Guidance and Counselling, Higher Teacher Training College Bambili, University of Bamenda, Cameroon
}

Copyright $(2016$ by authors, all rights reserved. Authors agree that this article remains permanently open access under the terms of the Creative Commons Attribution License 4.0 International License

\begin{abstract}
The study examined the various forms of violence dominant in Cameroon schools, its perpetrators and their reactions to the practice, through a questionnaire survey administered to 500 adolescent students within the age range of 11 to 20 years. This sample was drawn from two secondary schools in the North West Region of Cameroon, (one day and the other boarding). We worked from the premise that violence was a common practice but subject to sanctions in Cameroon schools as in other parts of the world. Its' practice even in the face of deterrent school sanctions has persisted despite its negative impact on personality development. Data from the survey was analyzed by use of simple percentages with a comparison of its practice between boys and girls and between types of schools. Both physical and verbal forms of violence were reported to be dominant in the schools, with no significant difference in either of them. More boys than girls were equally reported to be involved in practicing acts of violence, with a high rate of violence on boys by boys followed by violence on girls by boys. Although sanctions on violence exist and are similar in both types of schools, its dimension was indicated to be higher in boarding schools than it is the case in day schools. Given that violence is dominant in the schools despite the sanctions administered by school authorities, the study suggests a home and school-based counseling approach that favors orientation against the practice in Cameroon schools. This can be reinforced through a national education policy that discourages violence.
\end{abstract}

Keywords Violence, Adolescent Students, Sanctions, Negative Impact, Types of Schools, Forms of Violence, Acts of Violence, Counseling Approach

\section{Introduction}

Violence is a prevalent practice among students in many secondary schools in Cameroon as is the case in many other parts of the world. It is dominantly victimization of one person by another; expressed in the form of physical or verbal violence. Sepiel[1] has estimated that about 2 million children and youths all over the world are being abused by their peers. Often it is done as retaliation to earlier similar action and also as a show of physical strength among peers or counterparts. The perpetrators' interest is always to ridicule the weak and those with low self-esteem that may want to shy away from this practice. Students take delight in perpetrating violence without thinking of its repercussions. Such manifestations have been described by Woods[2] as a defensive and or retaliatory response to perceived provocation from peers as well as unprovoked deliberate goal-directed behavior used to influence a peer.

It is reactive and proactive and is often a response to negative actions in socialization experiences as explained by Santrock[3]. It has a bearing on what Nsamenang,[4] describes as a cultural curriculum- a situation where violence is considered as a tradition within the community and by extension the school system (where those who have been violated seek for opportunities at that moment or later to give it back).

In the Cameroonian school system, children suffer from different forms of violence from their peers, and in response, the school authorities prescribe sanctions against perpetrators of the act. Whenever incidents of violence occur, school authorities do not fail to remind students of the likely implications of such acts. Despite these precautionary measures, there is seemingly no reduction in violent practices in the schools. Such a habit goes a long way to affect students' social behavior and restrains healthy human relationships.

This study was done with inspiration from personal observation of students ' violent behavior in schools (despite efforts to eradicate the practice), as well as from related literature. Ncontsa and Shumba[5] following their study on the nature, causes and effects of school violence in South Africa, revealed that different forms of violence exist in schools producing such effects like loss of concentration, poor academic performance and depression on the students. Given the above picture and knowledge of what its effects can be on personality development e.g. depression, rejection, low self-esteem ,crime etc , and 
considering that focus in Cameroon is largely on gender violence, this study focused on school violence(often neglected )but seemingly has some damaging effects on human development. Violence in school is certainly dangerous to a growing child; given that at that stage habits are formed. School violence should be given serious attention because it could become a base for greater acts of violence in society in future.

This study was done with a great desire to identify dominant acts of violence among children, know its great perpetrators and understand their reactions to it, and eventually use the results as a spring board for encouraging greater intervention by all school stakeholders to curb school violence.

Theoretically, this study is linked to the principle of Harkness` ecological principle cited by Nsamenang, [4] He explains that a child is at the centre of development with his particular set of inherited dispositions like temperaments. $\mathrm{He}$ further explains three subsystems that surround the child's reactions (the setting or the physical and social contexts in which the child lives, the custom or culturally determined rearing and educational practices and finally, the psychological characteristics of care takers). That ties with this study because children generally grow within a setting that has a culture and care givers whose attitude can influence behavior- violent behavior not exempted. In addition, the 2006 Theory and Application by Dekeseredy and Perry, says that humans are naturally inclined to acts of violence which are ultimately the product of a failure of constraint or control of emotions

The study was therefore a descriptive survey and the data was collected from a randomly selected sample of 500 students of 11 to 20 years old. They were drawn from day and boarding schools of the study area.

\section{Results}

\section{Existence of Violence in Schools}

A total of $91 \%$ of the students acknowledged the prevalence of both physical and verbal forms of violence in schools

\section{The More Involved by Sex and School}

More boys (38\%) than girls (18\%) are reported to be involved in the practice .More boys $(34 \%)$ in day schools were involved while more girls (26\%) than boys (21\%) were involved in boarding schools

\section{The More Violated by Gender}

The boys $\{31 \%\}$ were reported to be the more violated by boys. This was preceded by girls on girls $(26 \%)$ in both schools.

\section{The More Violated By Gender and School}

More girls $(32 \%)$ in day schools were violated by boys and in boarding schools more girls $(30 \%)$ were highly violated by their counterparts. The difference in the practice of violence in both schools by gender was thus less significant.

\section{Response to Acts of Violence}

The students (68.6\%) reported being quite hurt by acts of violence inflicted on them, $26.8 \%$ of them being helpless. As a consequence, the children have become, timid and frightened

\section{School Sanctions}

Talking to students about this practice was reported to be a common phenomenon, followed by suspension and eventual dismissal of perpetrators from schools if the act persists.

\section{Discussion}

From the analysis of the results of this survey, violence is a common phenomenon in Cameroon schools and takes the form of physical or nonverbal violence. This could probably be because onlookers who are usually their peers cheer them up, and its perpetrators certainly enjoy it. They say, "it is easy, works and makes them feel powerful."

The boys were reported to be the greater perpetrators of the various forms of violence on both boys and girls. This confirms the general belief in Cameroon that boys are aggressive and assertive - a true display of male chauvinism.

\section{Existence of Violence in Schools}

Students have a tradition that keeps violence alive. The college tradition of senior and junior student relationship is meant to ensure respect. Junior students are expected to respect the senior ones considering that one level is higher than the other.

Unfortunately, such practice as found in schools, breeds contempt and violence among students as the young are victimized by the old (but should not complain or agitate). This practice confirms Nsamenang's[4] view of children as having their world where they are not merely active accommodators but are also creative and social producers of their own world.

Despite the negative influences of this practice on both academic and social development, students have kept it alive as a form of revenge. The students eagerly wait for their turn as senior students to retaliate on the junior ones. There is thus a firm commitment by students to continue the act, hence that has kept the practice alive despite all efforts by school authorities to stop it.

\section{Strange Phenomenon}

Reporting that boys were more violent than girls could be largely accepted in this context, but when girls are reported to be more violent on boys as was reported for day schools, it is seen as unusual. The girls are known to be the 
weaker sex, who by nature are humble and gentle and therefore should not practice violence. This brings us to terms with the principle that the environment has a positive or negative influence on behavior. This position assumed by the girl child could be a defense mechanism against a hostile environment that constantly uses violence and puts her under stress, thus girls' assertiveness could also be a way of warding off violent boys. Violence is therefore seen by many students as medium for show off, self-worth and maintenance of ego. They would not want to be considered weak; hence, retaliation and violence become imperative

\section{Culture and Violence}

In Cameroon and most of Sub Saharan Africa, violence is not often sanctioned within the society. The victims of violence who run home to complain and express their disappointment are instead challenged with such questions like-"What did you do?", "So you could not fight back?", "Are you a coward?" .This practice is thus encouraged and seen by almost all as normal. The reason for this approach is to encourage children to become independent and face such challenges and problems rather than running to parents to complain every time.

Although the home by this practice encourages independence and discourages cowardice, we must indicate here that morality to some extent has been undermined. Consequently, attempts by school authorities to stop the phenomenon, make little or no sense to the students who would want to maintain their self-esteem at any price.

\section{School Sanctions on Violence}

The results of the study acknowledged that the practice of violence is sanctioned in schools and the sanctions are varied. Each of them is applied depending on the gravity of the act. The sanctions are usually declared in public according to the tradition of most Cameroonian schools. Often, it is done during school General Assembly meetings where all members of the school community are present. This method is used as a deterrent measure against violence and its perpetrators and at the same time, to humiliate those sanctioned. Humiliated students do not only suffer the pain of physical punishment and missing of class lessons to do punishment, but go through some level of stress that affects their development.

\section{Intervention Strategy Suggested}

Sanctioning violent behavior in Cameroon schools was acknowledged by the results of this study. Talking to students against it was reported to be the most commonly used measure by the schools and particularly in day schools.
On the other hand, suspension and dismissal as forms of punishment have so far not put a significant stop to violence. The use of guidance and counseling could be a preferable approach to the eradication or reduction of violence in Cameroonian schools. Counseling will go with education, create awareness of the implications of violence on human development and eventually lead to adjustment of thought and behavior. It should take the form of home and school-based counseling, which should be separately done so that from these perspectives a firm intervention approach will be developed. To ensure its effectiveness, such an intervention approach should be established as a policy within the Cameroon school system.

The counseling process within the home context should not only bring out the disadvantages of violent acts, but should emphasize the fact that children from either anti-authoritarian or excessively permissive homes are likely to be difficult. Such homes as stipulated by McWhirter[6] produce anti- socialized adults instead of responsible citizens. It should further hammer on the family and home environment as the place where violence can begin thus it should be the initial place where violence is discouraged.

Within the schools, the quality of counseling should strive to instill discipline in the children and reduce sanctions. Discipline as portrayed by Nsamenang,[4] is the purpose of education and develops disciplined and responsible behavior which can largely reduce violence in the school community and improve on its tone. Individuals who acquire discipline will not vent their anger on others. They will build internal discipline that will shape their thought and action. It should also correct the teacher's notion of correction that goes with punishment - a temporary measure that is likely to foster violence. A teacher who spends time establishing a friendly relationship with students, is likely to find through such a relationship other positive results both in learning and behavior (Lowenstein,[7] This approach should also recognize the existence of "peer group norms" which the adolescent will respect to the letter.

\section{Conclusions}

Violence in schools does not only inflict pain on the abused, but will inhibit growth of some innate tendencies in the adolescent. This may lead to personality disorders which impact on academic performance and relationships in the school, home and community are far reaching.

The fight against violence above all, should be extensive beginning from the home to the school. When children are educated against this practice early enough, it will be a step towards greatly reducing it and inculcating in them the value of love and respect for one another. 


\section{REFERENCES}

[1] Spiel C. Victimisation in Children and Youth. Workshop Presentation- ISSBD Wurzburg Germany; 2008

[2] Woods R. A Critique of the Concept of Accuracy in Theory and Psychology 2010

[3] Santrock J.W. Child Development. McGraw-Hill Company U.S.A.1999 P. $47 \& 57$

[4] Nsamenang A.B. Human Development. An Educational
Perspective. H.D.R.C. Publications Bamenda Cameroon. 1999 .p. 266-268.

[5] Ncontsa V.N. and Shumba A. Nature? Causes and Effects of School Violence. South Africa Pretoria 2013

[6] McWhirter et al. At-Risk Youth: A Comprehensive Response. Books/Cole Publishing Company U.S.A.1998 p. 50, 162-163)

[7] Lowenstein L. Violence in Schools and Treatment. National Association of School Masters Britain. 1972. P. 28-31 